\title{
Airway pressure release ventilation versus low tidal volume ventilation for patients with acute respiratory distress syndrome/ acute lung injury: a meta-analysis of randomized clinical trials
}

\author{
Xi Zhong, Qin Wu, Hao Yang, Wei Dong, Bo Wang, Zhongwei Zhang, Guopeng Liang \\ Department of Critical Care Medicine, West China Hospital of Sichuan University, Chengdu, China \\ Contributions: (I) Conception and design: X Zhong, Z Zhang, G Liang; (II) Administrative support: B Wang; (III) Provision of study materials or \\ patients: X Zhong, W Dong; (IV) Collection and assembly of data: X Zhong, Q Wu; (V) Data analysis and interpretation: X Zhong, H Yang; (VI) \\ Manuscript writing: All authors; (VII) Final approval of manuscript: All authors. \\ Correspondence to: Zhongwei Zhang; Guopeng Liang. Department of Critical Care Medicine, West China Hospital of Sichuan University, 37 Guoxue \\ Lane, Wuhou District, Chengdu, China. Email: hxzzw2020@163.com; liangguopeng007@163.com.
}

\begin{abstract}
Background: It is uncertain whether airway pressure release ventilation (APRV) is better than low tidal volume ventilation (LTVV) for patients with acute respiratory distress syndrome (ARDS). The purpose of this meta-analysis was to compare APRV and LTVV on patients with ARDS.

Methods: Randomized controlled trials (RCTs) comparing outcomes in ARDS ventilator therapy with APRV or LTVV were identified using Medical Literature Analysis and Retrieval System Online (MEDLINE), Excerpta Medica Database (EMBASE), Cumulative Index to Nursing and Allied Health Literature (CINAHL), Web of Science, the Cochrane Library, and The Chinese Biomedicine Literature Database (SinoMed) from inception to March 2019.

Results: A total of 7 RCTs with a 405 patients were eligible for our meta-analysis. The results revealed that APRV was associated with lower hospital mortality [405 patients; odds ratio (OR), 0.57 ; $95 \%$ confidence interval (CI), 0.37-0.88; $\mathrm{P}=0.01$ ], a shorter time of ventilator therapy [373 patients; mean difference (MD), 5.36; 95\% CI, 1.99-8.73; $\mathrm{P}=0.002$ ], and intensive care unit (ICU) stay (315 patients; $\mathrm{MD},-4.50$; $95 \% \mathrm{CI}$, -6.56 to $-2.44 ; \mathrm{P}<0.0001$ ), better respiratory system compliance on day 3 (202 patients; $\mathrm{MD}, 8.19 ; 95 \% \mathrm{CI}$, 0.84-15.54; $\mathrm{P}=0.03)$, arterial partial pressure of oxygen/fraction of inspired oxygen $(\mathrm{PaO} 2 / \mathrm{FiO} 2)$ on day 3 (294 patients; $M D$, 44.40; 95\% CI, 16.05-72.76; $\mathrm{P}=0.002$ ), and higher mean arterial pressure (MAP) on day 3 (285 patients; MD, 4.18; 95\% CI, 3.10-5.25; $\mathrm{P}<0.00001)$. There was no statistical difference in the incidence of pneumothorax (170 patients; OR, 0.40; 95\% CI, 0.12-1.34; $\mathrm{P}=0.14$ ).

Conclusions: The meta-analysis showed that APRV could reduce hospital mortality, duration of ventilation and ICU stay, improve lung compliance, oxygenation index, and MAP compared with LTVV for patients with ARDS. We found APRV to be a safe and effective ventilation mode for patients with ARDS.
\end{abstract}

Keywords: Acute respiratory distress syndrome (ARDS); acute lung injury; airway pressure release ventilation (APRV); low tidal volume ventilation (LTVV)

Submitted Sep 15, 2020. Accepted for publication Nov 25, 2020.

doi: $10.21037 /$ atm-20-6917

View this article at: http://dx.doi.org/10.21037/atm-20-6917

\section{Introduction}

Acute respiratory distress syndrome (ARDS) is an extremely dangerous lung condition that leads to low blood oxygen levels, and is commonly caused by sepsis, pneumonia, aspiration, and trauma (1). Despite great improvements in mechanical ventilation in recent years, the mortality rate of ARDS is still high (40\%) (2). Low tidal volume ventilation (LTVV), optimum positive end-expiratory 
pressure, permissive hypercapnia, lung recruitment, and the prone position are common treatments for ARDS (3-6). The prognosis of ARDS is closely related to mechanical ventilation airway pressure (7). Severe ARDS, even when treated with a LTVV strategy, can result in high airway pressure and a poor prognosis. Airway pressure release ventilation (APRV) was first conceptualized by Stock and Downs in 1987 (8). The technique is a pressure-limited, time-cycled mode of ventilation, based on continuous positive airway pressure (CPAP) (9). The approach involves long duration $\left(\mathrm{T}_{\text {high }}\right)$ high airway pressure $\left(\mathrm{P}_{\text {high }}\right)$ and short duration $\left(\mathrm{T}_{\text {low }}\right)$ low airway pressure $\left(\mathrm{P}_{\text {low }}\right)$. Patients are able to maintain spontaneous breathing during ventilation with biphasic positive airway pressure (BIPAP) ventilation via a special time switching mode (10). Potential advantages of APRV in ARDS include reduction in atelectrauma through decreased cyclical recruitment and de-recruitment, increased recruitment of lung units due to an increase in functional residual capacity, unrestricted spontaneous breathing, which improves ventilation/perfusion (V/Q) matching, and decreased sedation and neuromuscular blockade requirements (11-14).

Zhou et al. found that APRV could improve oxygenation and respiratory system compliance, decrease plateau pressure $\left(\mathrm{P}_{\text {plat }}\right)$ and reduce the duration of both mechanical ventilation and intensive care unit (ICU) stay in patients with ARDS, as compared with LTVV (15). However, the benefits of APRV over conventional ventilation need to be confirmed. Many prospective randomized controlled trials (RCTs) and retrospective clinical trials have evaluated the feasibility, safety, and efficacy of APRV and LTVV for patients with ARDS. However, there are still some controversies in recent research for the two different ventilation modes. The aim of our systematic review and meta-analysis was to confirm whether patients with ARDS have better primary outcomes (death during hospitalization and the number of ventilator-free days by day 28) when ventilated using APRV compared with LTVV.

We present the following article in accordance with the PRISMA reporting checklist (available at http://dx.doi. org/10.21037/atm-20-6917).

\section{Methods}

Protocol development and review publication were performed in accordance with the Preferred Reporting Items for Systematic Reviews and Meta-Analysis (PRISMA) guidelines (16).

\section{Literature search strategy}

We searched the data from Medical Literature Analysis and Retrieval System Online (MEDLINE), Excerpta Medica Database (EMBASE), Cumulative Index to Nursing and Allied Health Literature (CINAHL), Web of Science, the Cochrane Library, and Chinese Biomedicine Database to March 2019 for potentially eligible studies. The following search terms were used: "acute respiratory distress syndrome" or "acute lung injury (ALI)" or "ARDS" or "ALI"; "airway pressure release ventilation" or "APRV"; "low tide volume ventilation" or "small tide volume ventilation" or "LTVV" or "STVV". Language was restricted to Chinese and English, and all studies were conducted on humans. We included only RCTs.

\section{Study eligibility criteria}

We included all RCTs evaluating the use of APRV compared with LTVV for patients with ARDS. All patients were adults (age $\geq 18$ years) diagnosed with ARDS/acute lung injury, defined as $\mathrm{PaO}_{2} / \mathrm{FiO}_{2}<300 \mathrm{mmHg}$. We excluded patients with cardiogenic pulmonary edema, asthma, and severe chronic lung diseases. We also excluded case reports, literature reviews, and observational studies. The search was restricted to the Chinese and English languages, and all studies were conducted on humans.

\section{Outcomes measured}

The primary outcomes of this study were death during hospitalization and the number of ventilator-free days by day 28. Secondary outcomes were respiratory mechanical parameters (respiratory system compliance on day 3), hemodynamics [mean arterial pressure (MAP) on day 3], oxygenation $\left(\mathrm{PaO}_{2} / \mathrm{FiO}_{2}\right.$ on day 3$)$, length of ICU stay, and clinical complication (pneumothorax).

\section{Selection of studies, data extraction, and quality assessment}

All procedures were independently reviewed by two authors (Hao Yang, Qin Wu) in accordance with the prespecified inclusion criteria. Data extraction and quality assessment were based on the Cochrane risk of bias tool (17). The general information extracted included study characteristics (age, gender, design, ventilator mode, sample size, acute physiology and chronic health enquiry (APACHE II) score, Murray score, $\mathrm{PaO}_{2} / \mathrm{FiO}_{2}$ at baseline, type of patients, and 


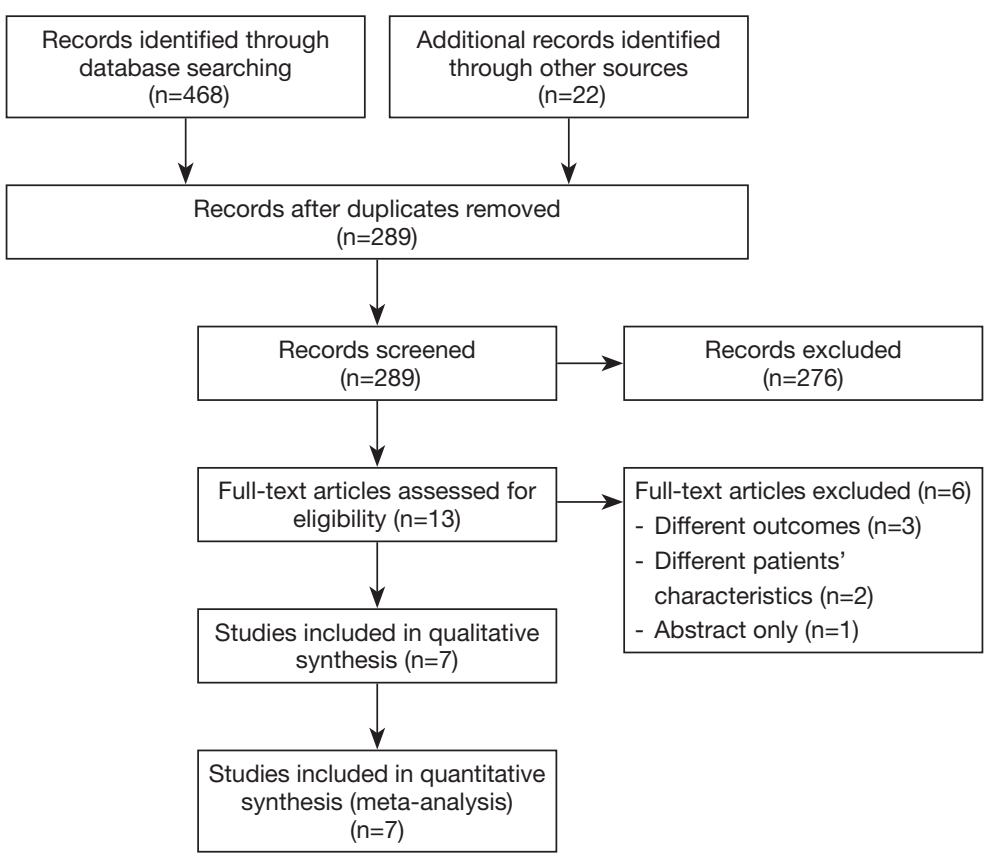

Figure 1 PRISMA flowchart. PRISMA, Preferred Reporting Items for Systematic Reviews and Meta-Analysis.

APRV initial setting), intervention and settings, adverse events, risk of bias, and outcome results. We contacted studies' authors for detailed data to calculate the mean and standard deviation (SD) for studies that reported only medians. If the authors did not provide detailed data, we estimated the mean and SD using the methods developed by Wan et al. (18). Any disagreements regarding data collection, data extraction, and quality assessment were resolved by consensus.

\section{Statistical analysis}

All individual outcomes were integrated with the metaanalysis software Review Manager (RevMan) version 5.3 (Cochrane Collaborative, Oxford, United Kingdom). Clinical heterogeneity was evaluated by qualitative assessment of study and intervention differences. Heterogeneity of the enrolled studies was evaluated by the Chi-square $\left(\chi^{2}\right)$ test and a $\mathrm{P}$ value of 0.1 was considered to indicate a significant difference. We used $\mathrm{I}^{2}$ values to evaluate statistical heterogeneity, with values of $25 \%, 50 \%$, and $75 \%$ representing low, moderate, and high degrees of heterogeneity, respectively.

Results were analyzed with the random-effects method, if significant heterogeneity $(\mathrm{P}<0.05$ was used to define statistically significant heterogeneity) was detected among the studies. Otherwise, a fixed-effects model was adopted. Dichotomous variables were analyzed using the MantelHaenszel method and were expressed as odds ratios (OR). Continuous variables were analyzed using the inverse variance random-effects model and were expressed as mean differences (MD).

Forest and funnel plots were used to show the outcome parameters and evaluate publication bias, respectively.

\section{Results}

\section{Study characteristics}

Our search yielded a total of 490 potential articles, of which 483 were excluded (Figure 1). A total of 7 RCTs with 405 patients in all met our inclusion criteria $(15,19-24)$. The characteristics of the 7 included studies are shown in Table 1. All of the studies were single-centered RCTs, and all included patients in this review were diagnosed with ARDS/ ALI. There was 1 study that included only trauma patients with ARDS/ALI (21), and 4 studies enrolled patients with moderate to severe ARDS (19,22-24). Comparison of APRV with volume-controlled LTVV was made in 3 studies $(15,20,23), 3$ studies compared APRV with synchronized intermittent mandatory ventilation and pressure support LTVV $(19,22,24)$, and 1 study compared APRV with 


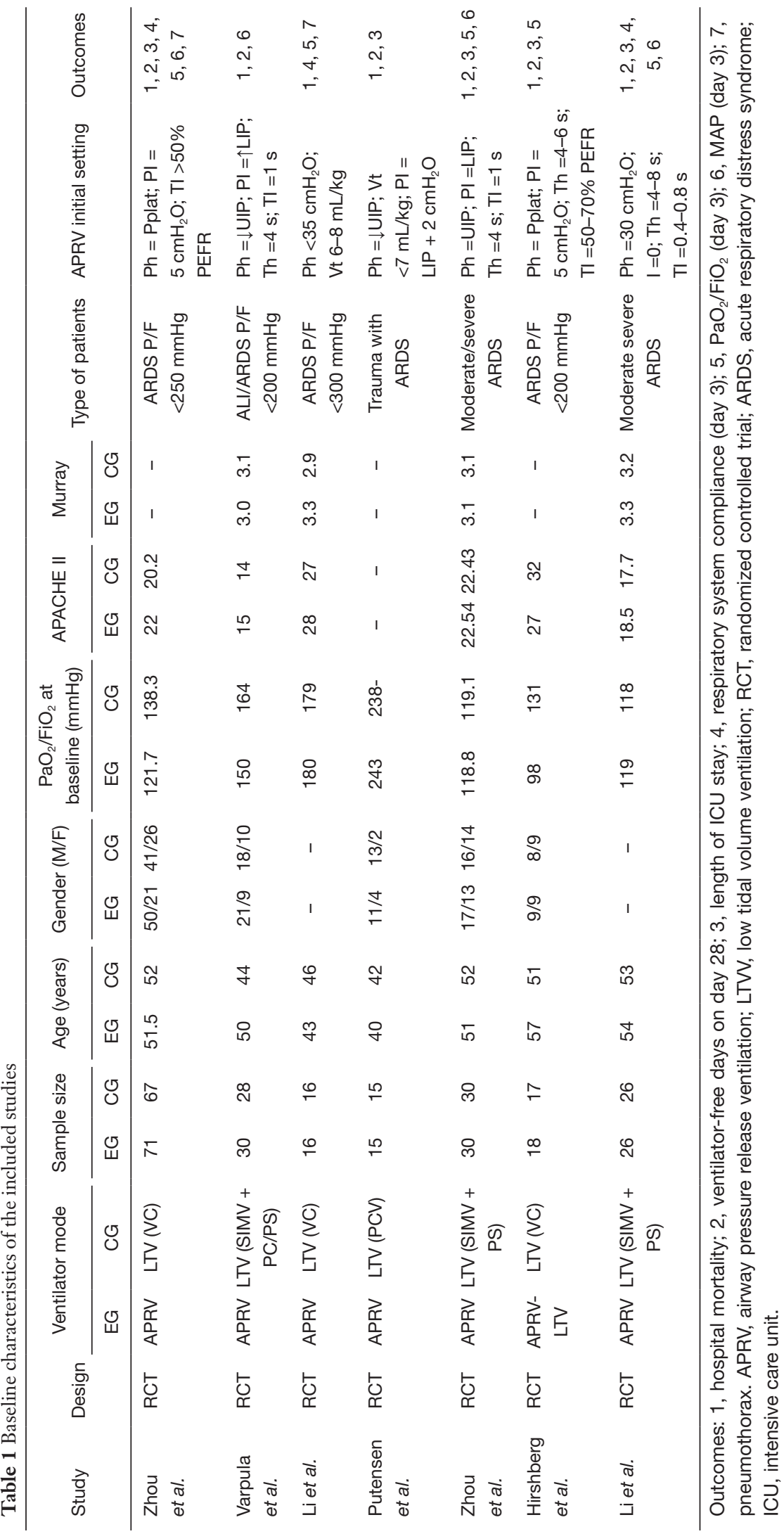


Table 2 Outcomes

\begin{tabular}{|c|c|c|c|c|c|}
\hline Outcomes & APRV $(n=206)$ & LTV $(n=199)$ & Analysis method & $95 \% \mathrm{Cl}$ & $P$ value \\
\hline Ventilator-free days at day 28 (days) & 190 & 183 & $\begin{array}{l}\text { IV, random, mean } \\
\text { difference }\end{array}$ & $5.36(1.99,8.73)$ & 0.002 \\
\hline $\begin{array}{l}\text { Respiratory system compliance at } \\
\text { day } 3\left(\mathrm{~mL} / \mathrm{cmH}_{2} \mathrm{O}\right)\end{array}$ & 104 & 98 & $\begin{array}{l}\text { IV, random, mean } \\
\text { difference }\end{array}$ & $8.19(0.84,15.54)$ & 0.03 \\
\hline $\mathrm{PaO}_{2} / \mathrm{FiO}_{2}$ at day 3 & 151 & 143 & $\begin{array}{l}\text { IV, random, mean } \\
\text { difference }\end{array}$ & $44.40(16.05,72.76)$ & 0.002 \\
\hline MAP at day $3(\mathrm{mmHg})$ & 146 & 139 & $\begin{array}{l}\text { IV, random, mean } \\
\text { difference }\end{array}$ & $4.18(3.10,5.25)$ & $<0.00001$ \\
\hline
\end{tabular}

APRV, airway pressure release ventilation; LTVV, low tidal volume ventilation; CI, confidence interval; ICU, intensive care unit; MAP mean arterial pressure.

pressure-controlled LTVV (21).

Regarding the initial APRV setting, a static pressurevolume $(\mathrm{P}-\mathrm{V})$ curve was used to identify lower and upper inflection points (LIP and UIP) and set pressure parameters in 3 studies $(19,21,22)$. Varpula et al. and Putensen et al. set $\mathrm{P}_{\text {high }}$ below UIP and $\mathrm{P}_{\text {low }}$ above LIP (19,21); Zhou et al. set $\mathrm{P}_{\text {high }}$ to UIP and $\mathrm{P}_{\text {low }}$ to LIP (22). Zhou et al. and Hirshberg et al. set $\mathrm{P}_{\text {high }}$ as $\mathrm{P}_{\text {plat, }}$ and $\mathrm{P}_{\text {low }}$ to $5 \mathrm{cmH}_{2} \mathrm{O}(15,23)$. Li et al. set $\mathrm{P}_{\text {high }}$ to $30 \mathrm{cmH}_{2} \mathrm{O}$ and $\mathrm{P}_{\text {low }}$ to 0 but used $\mathrm{P}-\mathrm{V}$ curve to set $\mathrm{T}_{\text {low }}$ to obtain an intrinsic end-expiratory pressure of $2 \mathrm{cmH}_{2} \mathrm{O}$ above LIP (24). Li et al. set $\mathrm{P}_{\text {high }}<35 \mathrm{cmH}_{2} \mathrm{O}$ (20), and Hirshberg et al. set $\mathrm{T}_{\text {low }}$ to reach $50-70 \%$ of the peak expiratory flow rate (23).

The statistical outcomes of the 7 RCTs included in this meta-analysis are presented in Table 2. All of the studies reported death during hospitalization $(15,19-24) ; 6$ studies discussed the number of ventilator-free days by day 28 $(15,19,21-24) ; 5$ studies noted length of ICU stay $(15,21-24)$ and $\mathrm{PaO}_{2} / \mathrm{FiO}_{2}$ on day $3(15,20,22-24) ; 4$ studies recorded MAP on day $3(15,19,22,24) ; 3$ studies addressed respiratory system compliance on day $3(15,20,24)$; and 2 studies discussed ventilation-related complications (pneumothorax) $(15,20)$.

\section{Risk of bias}

Table 3 shows the overall results of the quality assessment for the included studies. There were 5 studies deemed adequate regarding random sequence generation $(15,20,22-24)$, and
3 trials had a low risk of bias for allocation concealment $(15,19,23)$. Blinding was not possible for any studies owing to the nature of the intervention being investigated, which might have led to a high risk of performance bias $(15,19-24)$. None of the trials mentioned blinding in their outcome assessments, but all studies had complete outcomes data $(15,19-24)$. A low risk for reporting bias was detected in 4 studies $(15,20,23,24)$.

\section{Primary outcome}

The mortality rate of ARDS patients remained high. All 7 trials, involving 405 participants, reported death during hospitalization (15,19-24). The meta-analysis demonstrated that death during hospitalization was significantly lower in the APRV group (405 patients; OR, 0.57; 95\% CI, $0.37-0.88 ; \mathrm{P}=0.01$ ) (Figure 2). The number of ventilatorfree days by day 28 was reported in 6 studies (15,19,21-24). The results showed that APRV shortened the duration of ventilation in ARDS patients compared with LTVV (373 patients; MD, 5.36; 95\% CI, 1.99-8.73; $\mathrm{P}=0.002$ ) (Figure 3). Heterogeneity analysis showed that there was homogeneity in death during hospitalization $\left(\mathrm{I}^{2}=0\right)$ and high heterogeneity for the number of ventilator-free days on day $28\left(\mathrm{I}^{2}=85 \%\right)$.

\section{Secondary outcome}

Length of ICU stay was described in 5 studies (15,21-24). 
Table 3 Quality assessment of the included studies

\begin{tabular}{|c|c|c|c|c|c|c|c|}
\hline Study & $\begin{array}{l}\text { Random } \\
\text { sequence } \\
\text { generation } \\
\text { (selection bias) }\end{array}$ & $\begin{array}{c}\text { Allocation } \\
\text { concealment } \\
\text { (selection bias) }\end{array}$ & $\begin{array}{c}\text { Blinding of } \\
\text { participants } \\
\text { and personnel } \\
\text { (performance bias) }\end{array}$ & $\begin{array}{c}\text { Blinding of outcome } \\
\text { assessment } \\
\text { (detection bias) }\end{array}$ & $\begin{array}{l}\text { Incomplete } \\
\text { outcome data } \\
\text { (attrition bias) }\end{array}$ & $\begin{array}{l}\text { Selective } \\
\text { reporting } \\
\text { (reporting bias) }\end{array}$ & $\begin{array}{c}\text { Other } \\
\text { bias }\end{array}$ \\
\hline Zhou et al. & + & + & - & $?$ & + & + & + \\
\hline Varpula et al. & $?$ & + & - & $?$ & + & $?$ & $?$ \\
\hline Putensen et al. & $?$ & $?$ & - & $?$ & + & $?$ & - \\
\hline Zhou et al. & + & $?$ & - & $?$ & + & $?$ & + \\
\hline Hirshberg et al. & + & + & - & $?$ & + & + & + \\
\hline Li et al. & + & $?$ & - & $?$ & + & + & $?$ \\
\hline
\end{tabular}

+ , low risk of bias; -, high risk of bias; ?, unclear risk.

\begin{tabular}{|c|c|c|c|c|c|c|c|c|c|c|}
\hline Study or Subgroup & \multicolumn{2}{|c|}{ APRV } & \multicolumn{2}{|l|}{ LTV } & \multicolumn{3}{|c|}{ Odds Ratio } & \multicolumn{2}{|c|}{$\begin{array}{c}\text { Odds Ratio } \\
\mathrm{M}-\mathrm{H} \text {, Fixed, } 95 \% \mathrm{Cl}\end{array}$} & \\
\hline Hirshberg 2018 & 6 & 18 & 10 & 17 & $12.8 \%$ & $0.35[0.09,1.39]$ & & & F & \\
\hline Li JQ 2016 & 8 & 26 & 9 & 26 & $11.6 \%$ & $0.84[0.26,2.68]$ & & & & \\
\hline Li JW 2011 & 6 & 16 & 7 & 16 & $8.2 \%$ & $0.77[0.19,3.17]$ & & & & \\
\hline Putensen 2001 & 3 & 15 & 4 & 15 & $6.0 \%$ & $0.69[0.12,3.79]$ & & & & \\
\hline Varpula 2004 & 5 & 30 & 5 & 28 & $8.0 \%$ & $0.92[0.24,3.59]$ & & & & \\
\hline Zhou XZ 2017 & 5 & 30 & 10 & 30 & $15.5 \%$ & $0.40[0.12,1.36]$ & & & F & \\
\hline Zhou YF 2017 & 17 & 71 & 26 & 67 & $37.9 \%$ & $0.50[0.24,1.03]$ & & $\rightarrow$ & & \\
\hline Total $(95 \% \mathrm{CI})$ & & 206 & & 199 & $100.0 \%$ & $0.57[0.37,0.88]$ & & & & \\
\hline Total events & 50 & & 71 & & & & & & & \\
\hline $\begin{array}{l}\text { Heterogeneity. } \mathrm{Chi}^{2}= \\
\text { Test for overall effect }\end{array}$ & $\begin{array}{l}2.06, d f \\
z=2.52\end{array}$ & $\begin{array}{l}=6(P \\
(P=0\end{array}$ & $\begin{array}{l}=0.91 \text {; } \\
.011\end{array}$ & $1^{2}=0 \%$ & & & 0.01 & APRV & 1 LTV & 100 \\
\hline
\end{tabular}

Figure 2 Death during hospitalization. APRV, airway pressure release ventilation; LTVV, low tidal volume ventilation; CI, confidence interval.

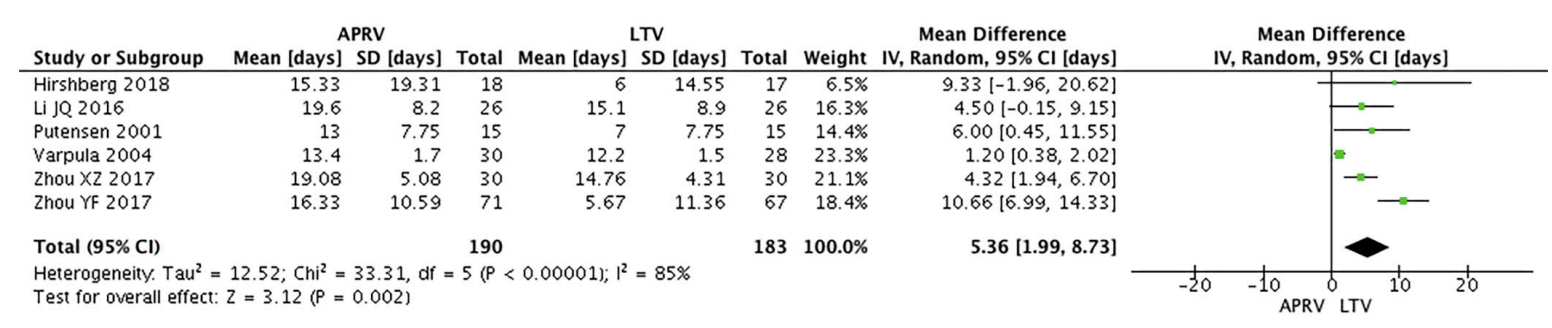

Figure 3 Ventilator-free days by day 28. APRV, airway pressure release ventilation; LTVV, low tidal volume ventilation; CI, confidence interval; SD, standard deviation.

The meta-analysis of these studies demonstrated that APRV decreased the ICU time for ARDS patients compared with LTVV (315 patients; MD, -4.50 ; 95\% CI, -6.56 to -2.44 ; $\mathrm{P}<0.0001$ ) (Figure 4).

Lung compliance refers to the degree of difficulty of changing the lung expansion under the action of external forces and is an important indicator of respiratory mechanics. Respiratory system compliance on day 3 was reported on in 3 trials $(15,20,24)$. The meta-analysis demonstrated that APRV improved lung compliance in patients with ARDS compared with LTVV (202 patients; MD, 8.19; 95\% CI, 0.84-15.54; $\mathrm{P}=0.03$ ) (Figure 5). 


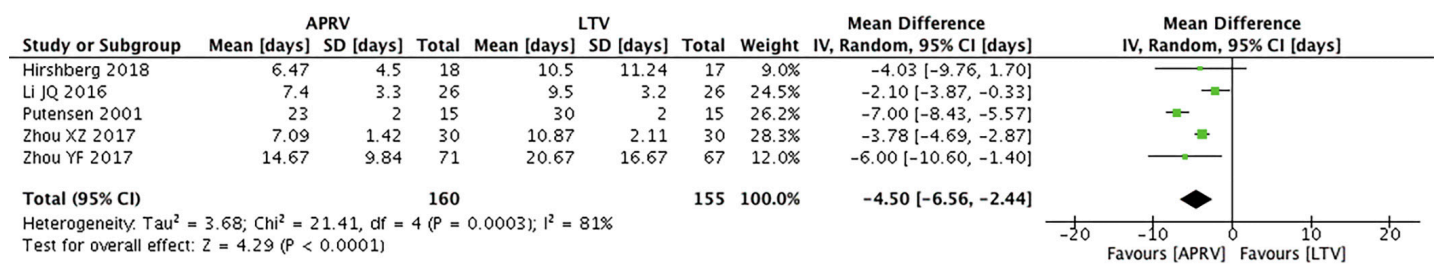

Figure 4 Length of ICU stay. ICU, intensive care unit; APRV, airway pressure release ventilation; LTVV, low tidal volume ventilation; CI, confidence interval; SD, standard deviation.

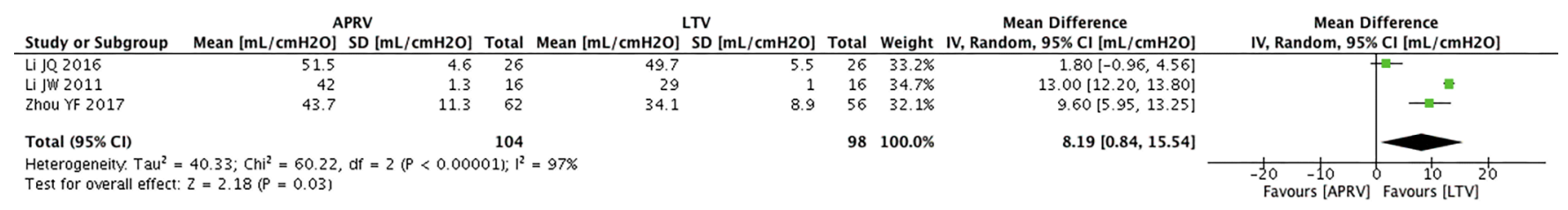

Figure 5 Respiratory system compliance on day 3. APRV, airway pressure release ventilation; LTVV, low tidal volume ventilation; CI, confidence interval; SD, standard deviation.

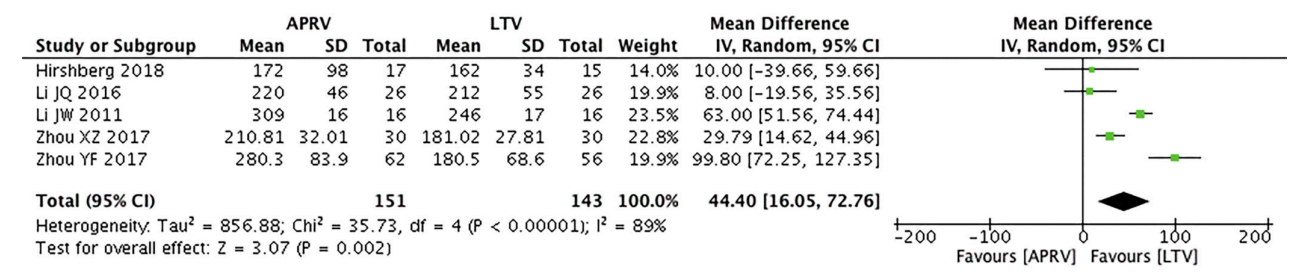

Figure 6 Oxygenation index on day 3. APRV, airway pressure release ventilation; LTVV, low tidal volume ventilation; CI, confidence interval; SD, standard deviation.

Oxygenation index reflects the patient's systemic oxygen supply, and patients with ARDS often have poor systemic oxygen supply. It was reported in 5 studies that oxygenation index $\left(\mathrm{PaO}_{2} / \mathrm{FiO}_{2}\right)$ values on day 3 of APRV were higher than those of the LTVV group (294 patients; MD, 44.40; 95\% CI, 16.05-72.76; $\mathrm{P}=0.002)$ (Figure 6) $(15,20,22-24)$.

The MAP was an important hemodynamic parameter for patients during treatment. The day 3 reading of MAP was mentioned in 4 trials, and it was significantly higher during APRV (285 patients; MD, 4.18; 95\% CI, 3.10-5.25; $\mathrm{P}<0.00001$ ) (Figure 7).

Pneumothorax was one of the most common complications in the treatment of ARDS patients. No significant difference between the ventilation modes was found in 2 trials (170 patients; OR, 0.40; 95\% CI, 0.12-1.34; $\mathrm{P}=0.14)$ (Figure 8$)(15,20)$.

\section{Discussion}

To our knowledge, this is the first meta-analysis of RCTs comparing the impact of APRV on ARDS with LTVV. Our study demonstrated that the APRV could reduce death during hospitalization, duration of ventilation and ICU stay, and improve lung compliance, oxygenation index, and MAP compared with LTVV, for patients with ARDS.

In 1967, Ashbaugh characterized ARDS as refractory hypoxemia and severe respiratory distress (25). The pathophysiology of ARDS includes severe inflammatory injury to the alveolar-capillary barrier, surfactant depletion, and loss of aeratable lung tissue, which leads immediately to profound hypoxemia, decreased lung compliance, and increased intrapulmonary shunting and dead space (26). Due to the severe lung injury, patients with ARDS often have a poor prognosis. Mechanical ventilation is currently 


\begin{tabular}{|c|c|c|c|c|c|c|c|c|c|c|}
\hline Study or Subgroup & & $\begin{array}{l}\text { PRV } \\
\text { SD [mmHg] }\end{array}$ & \multicolumn{4}{|c|}{ LTV } & Weight & \multirow{2}{*}{$\begin{array}{c}\text { Mean Difference } \\
\text { IV, Random, 95\% Cl [mm } \mathrm{mg}] \\
5.00[-3.43,13.43]\end{array}$} & \multicolumn{2}{|c|}{$\begin{array}{c}\text { Mean Difference } \\
\text { IV, Random, } 95 \% \mathrm{CI}[\mathrm{mmHg}]\end{array}$} \\
\hline Li JQ 2016 & 87 & 15 & 26 & 82 & 16 & 26 & $1.6 \%$ & & & \\
\hline Varpula 2004 & 83 & 2.53 & 28 & 79 & 1.87 & 27 & $84.3 \%$ & $4.00[2.83,5.17]$ & & \\
\hline Zhou $\times 22017$ & 87.01 & 7.14 & 30 & 82.12 & 6.51 & 30 & $9.7 \%$ & $4.89[1.43,8.35]$ & & \\
\hline Zhou YF 2017 & 92.8 & 14.9 & 62 & 87.1 & 13.6 & 56 & $4.4 \%$ & $5.70[0.56,10.84]$ & & \\
\hline Total $(95 \% \mathrm{CI})$ & & & 146 & & & 139 & $100.0 \%$ & $4.18[3.10,5.25]$ & & \\
\hline $\begin{array}{l}\text { Heterogeneity. Tau } \\
\text { Test for overall effect }\end{array}$ & $\begin{array}{l}0.00 ; \mathrm{Chi}^{2}=0.6 \\
Z=7.60(\mathrm{P}<0 .\end{array}$ & $\begin{array}{l}52, \mathrm{df}=3(\mathrm{P}= \\
.00001)\end{array}$ & $=0.891$ & $1^{2}=0 \%$ & & & & & $\begin{array}{l}-10-5 \\
\text { Favours [APRV] }\end{array}$ & $\begin{array}{cc} & 1 \\
\text { Favours [LTV] }\end{array}$ \\
\hline
\end{tabular}

Figure 7 MAP on day 3. MAP, mean arterial pressure; APRV, airway pressure release ventilation; LTVV, low tidal volume ventilation; CI, confidence interval; SD, standard deviation.

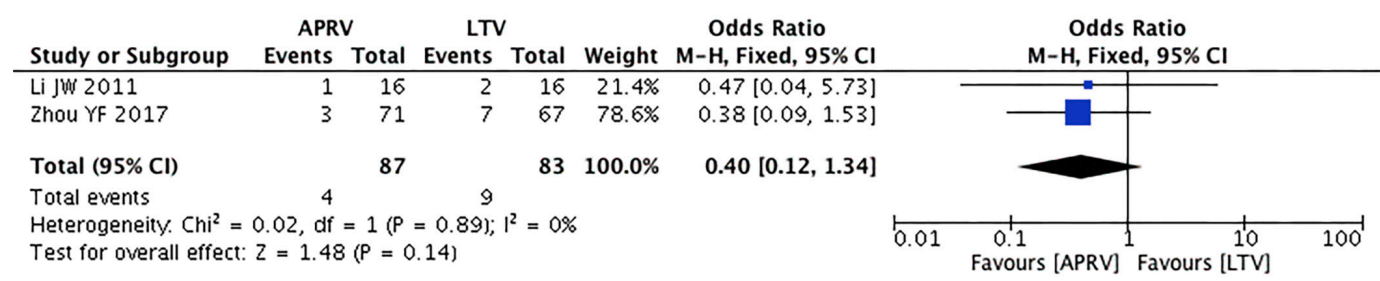

Figure 8 Pneumothorax. APRV, airway pressure release ventilation; LTVV, low tidal volume ventilation; CI, confidence interval; SD, standard deviation.

considered one of the most effective treatments for ARDS. LTVV is widely used and is considered the standard mechanical ventilation strategy. Different ventilator modes are used to improve the prognosis of ARDS. Since it was first proposed in 1987, the use of APRV has increased dramatically. The conceptual aim of APRV is to maximize and maintain alveolar recruitment by applying $\mathrm{P}_{\text {high }}$ for the majority of the ventilatory cycle and allowing spontaneous breathing (27). The purpose is to stabilize the open lung, reduce repetitive alveolar collapse and expansion, and thereby, limit ventilator-induced lung injury $(28,29)$. For ARDS patients, APRV is also considered a "protective lung ventilation" strategy (30). Several trials have shown that APRV increased alveolar ventilation, reduced dead space ventilation, and improved oxygenation, using a slightly higher airway pressure, smaller peak inspiratory pressure, fewer sedatives and lower ventilation time $(31,32,33)$.

In this meta-analysis, we attempted to compare the safety and efficacy of APRV with LTVV to demonstrate the superiority of APRV. In total, 7 RCTs comparing the primary outcomes using the two ventilation modes for ARDS were collected for the final pooled analysis. In the primary outcomes, death during hospitalization and the number of ventilator-free days by day 28 were significant advantages of APRV.

The data in this meta-analysis were in agreement with previously reported clinical and experimental findings indicating that using APRV in patients with ARDS significantly improved oxygenation and respiratory system compliance compared with LTVV $(34,35)$. The results of previous studies indicated that the process of recruitment and decruitment of lung units should be determined not only by pressure but also by time (36). For heterogeneous lung injury, during APRV, the proper elevated baseline airway pressure $\left(\mathrm{P}_{\text {high }}\right)$ and prolonged duration of $\mathrm{P}_{\text {high }}$ would optimize the recruitment of alveoli gradually over time, while preventing overinflation, and a brief release phase $\left(\mathrm{T}_{\text {low }}\right)$ could permit only partial lung volume loss during the release phase, avoiding cyclic alveoli collapse, and provide dynamic homogeneity $(27,37)$. These are the theoretical bases for improved oxygen and lung compliance. In Zhou et al. and $\mathrm{Li}$ et al.'s research, $\mathrm{PaO}_{2} / \mathrm{FiO}_{2}$ on day 3 in the APRV group were $280.3 \pm 83.9$ and $309 \pm 16 \mathrm{mmHg}$, respectively, and the $\mathrm{PaO}_{2} / \mathrm{FiO}_{2}$ values were significantly higher in both studies than in 3 other studies $(15,20,22-24)$. The selection criteria of enrolled patients were a $\mathrm{PaO}_{2} / \mathrm{FiO}_{2} \leq 250$ in Zhou et al.'s trial and $\mathrm{PaO}_{2} / \mathrm{FiO}_{2} \leq 300$ in $\mathrm{Li}$ et al.'s trial, while the $\mathrm{PaO}_{2} / \mathrm{FiO}_{2}$ value in the ARDS patients in 3 other studies was set at $\leq 200$. The difference in the selection criteria determined the difference in the studies' results.

Breathing and circulation complement and affect each other. Putensen et al. found that lower pleural pressure values during spontaneous breathing may also 
be responsible for the better hemodynamics parameters observed during APRV, with increased venous return, increased preload, and consequently, increased cardiac output (21). Our study found that MAP on day 3 was significantly higher during APRV (285 patients, $\mathrm{MD}=4.18$, 95\% CI, 3.10-5.25; $\mathrm{P}<0.00001$ ), and our meta-analysis findings were consistent with those in previous studies. The better breath and circulation indicators described in the APRV group could explain why the length of ICU stay was shorter in this group compared with the TLV group. Otherwise, there were no significant differences regarding pneumothorax. These results might be attributed to the improved ARDS treatment and the small number of enrolled studies.

There were also limitations related both to our study and to the inherent nature of meta-analysis. We included seven RCTs, only four studies had a low risk of bias $(15,20,23,24)$, the small number of enrolled studies which might cause publication bias. Some studies did not provide specific data for the outcomes evaluated in our review. The APRV parameter settings varied considerably among the included trials. APRV had evolved into a highly sophisticated, physiology-driven, dynamic mechanical breath profile with precise settings, which might cause a possibility of knowledge bias by the staff. Finally, most of the included trials were of small sizes except for Zhou et al.'s study $(\mathrm{n}>100)(15)$, which might have influenced the reliability and validity of our conclusions.

\section{Conclusions}

The meta-analysis showed that the APRV reduced death during hospitalization, duration of ventilation, and ICU stay, and improved lung compliance, oxygenation index, and MAP compared with LTVV for patients with ARDS. It was shown that APRV is a safe and effective ventilation mode for patients with ARDS.

\section{Acknowledgments}

We acknowledge all staff who offered help for this study and particularly acknowledge Qiao Wang, from the Department of Medical Statistics in Sichuan University, for providing advice regarding the literature search strategy and the data analysis.

Funding: This work was supported by the Provincial Science and Technology Department Project in Sichuan (2020YFS0164).

\section{Footnote}

Reporting Checklist: The authors have completed the PRISMA reporting checklist. Available at http://dx.doi. org/10.21037/atm-20-6917

Conflicts of Interest: All authors have completed the ICMJE uniform disclosure form (available at http://dx.doi. org/10.21037/atm-20-6917). The authors have no conflicts of interest to declare.

Ethical Statement: The authors are accountable for all aspects of the work in ensuring that questions related to the accuracy or integrity of any part of the work are appropriately investigated and resolved.

Open Access Statement: This is an Open Access article distributed in accordance with the Creative Commons Attribution-NonCommercial-NoDerivs 4.0 International License (CC BY-NC-ND 4.0), which permits the noncommercial replication and distribution of the article with the strict proviso that no changes or edits are made and the original work is properly cited (including links to both the formal publication through the relevant DOI and the license). See: https://creativecommons.org/licenses/by-nc-nd/4.0/.

\section{References}

1. ARDS (acute respiratory distress syndrome) symptoms, causes, and life expectancy (Internet). Medicine Net. 2018. Available online: https://www.medicinenet.com

2. Roy S, Habashi N, Sadowitz B, et al. Early airway pressure release ventilation prevents ARDS-a novel preventive approach to lung injury. Shock 2013;39:28-38.

3. Peck MD, Koppelman T. Low-tidal-volume ventilation as a strategy to reduce ventilator-associated injury in ALI and ARDS. J Burn Care Res 2009;30:172-5.

4. Beitler JR, Shaefi S, Montesi SB, et al. Prone positioning reduces mortality from acute respiratory distress syndrome in the low tidal volume ear: a meta-analysis. Intensive Care Med 2014;40:332-41.

5. Wheeler DS, Dewan M, Maxwell A, et al. Staffing and workforce issues in the pediatric intensive care unit. Transl Pediatr 2018;7:275-83.

6. Curley G, Hayes M, Laffey JG. Can 'Permissive' hypercapnia modulate the severity of sepsis-induced ALI/ ARDS? Crit Care 2011;15:212.

7. Girard TD, Bernard GR. Mechanical ventilation in ARDS: 
a state-of-the-art review. Chest 2007;131:921-9.

8. Downs JB, Stock MC. Airway pressure release ventilation: a new concept in ventilatory support. Crit Care Med 1987;15:459-61.

9. Ware LB, Matthay MA. The Acute Respiratory Distress Syndrome. N Engl J Med 2000;342:1334-49.

10. Modrykamien A, Chatburn R, Ashton R. Airway pressure release ventilation: An alternative mode of mechanical ventilation in acute respiratory distress syndrome. Cleve Clin J Med 2011;78:101-10.

11. Putensen C, Mutz NJ, Putensen-Himmer G, et al. Spontaneous breathing during ventilatory support improves ventilation-perfusion distributions in patients with acute respiratory distress syndrome. Am J Respir Crit Care Med 1999;159:1241-8.

12. Sydow M, Burchardi H, Ephraim E, et al. Long-term effects of two different ventilatory modes on oxygenation in acute lung injury. Comparison of airway pressure release ventilation and volume-controlled inverse ratio ventilation. Am J Respir Crit Care Med 1994;149:1550-6.

13. Facchin F, Fan E. Airway pressure release ventilation and high-frequency oscillatory ventilation: potential strategies to treat severe hypoxemia and prevent ventilator-induced lung injury. Respir Care 2015;60:1509-21.

14. Maung AA, Kaplan LJ. Airway pressure release ventilation in acute respiratory distress syndrome. Crit Care Clin 2011;27:501-9.

15. Zhou Y, Jin X, Lv Y, et al. Early application of airway pressure release ventilation may reduce the duration of mechanical ventilation in acute respiratory distress syndrome. Intensive Care Med 2017;43:1648-59.

16. Moher D, Liverati A, Tetzlaff J, et al. The PRISMA Group (2009) preferred reporting items for systematic reviews and meta-analysis, The PRISMA statement. PloS Med 2009;6:e1000097.

17. Higgins JP, Green SA. Cochrane Handbook for Systematic Reviews of Interventions, Version 5.1.0 (updated March 2011). Oxford(UK): The Cochrane Collaboration; Available online: http://www.handbookcochrane.org (accessed 2016 Dec 6).

18. Wan X, Wang W, Liu J, et al. Estimating the sample mean and standard deviation from the sample size, median, rang and/or interquartile range. BMC Med Res Methodol 2014;14:135.

19. Varpula T, Valta P, Niemi R, et al. Airway pressure release ventilation as a primary ventilatory mode in acute respiratory distress syndrome. Acta Anaesthesiol Scand 2004;48:722-31.
20. Li JW, Liang Y. The comparative observation of lung protective effect between APRV and low tide volume (A/C) ventilation mode on ARDS patients. BMU J 2011;34:127-9.

21. Putensen C, Zech S, Wrigge H, et al. Long-term effects of spontaneous breathing during ventilatory support in patients with acute lung injury. Am J Respir Crit Care Med 2001;164:43-9.

22. Zhou XZ. Clinical observation of airway pressure release ventilation in moderate and severe acute respiratory distress syndrome. Chin J Lung Dis 2017;10:431-5.

23. Hirshberg EL, Lanspa MJ, Peterson J, et al. Randomized Feasibility Trial of a Low Tidal Volume-Airway Pressure Release Ventilation Protocol Compared with Traditional Airway Pressure Release Ventilation and Volume Control Ventilation Protocols. Crit Care Med 2018;46:1943-52.

24. Li JQ, Li N, Han GJ, et al. Clinical research about airway pressure release ventilation for moderate to severe acute respiratory distress syndrome. Eur Rev Med Pharmacol Sci 2016;20:2634-41.

25. Ashbaugh DG, Bigelow DB, Petty T, et al. Acute respiratory distress in adults. Lancet 1967;2:319-23.

26. Wong JJM, Leong JY, Lee JH, et al. Insights into the immuno-pathogenesis of acute respiratory distress syndrome. Ann Transl Med 2019;7:504.

27. Kollisch-Singule M, Jain S, Andrews P, et al. Effect of airway pressure release ventilation on dynamic alveolar heterogeneity. JAMA Surg 2016;151:64-72.

28. Sahetya SK, Goligher EC, Brower RG. Fifty years of research in ARDS. Setting positive end-expiratory pressure in acute respiratory distress syndrome. Am J Respir Crit Care Med 2017;195:1429-38.

29. Emr B, Gatto LA, Roy S, et al. Airway pressure release ventilation prevents ventilator-induced lung injury in normal lungs. JAMA Surg 2013;148:1005-12.

30. Jain SV, Kollisch-Singule M, Sadowitz B, et al. The 30year evolution of airway pressure release ventilation (APRV). Intensive Care Med Exp 2016;4:11.

31. Matsuzawa Y, Nakazawa K, Yamamura A, et al. Airway pressure release ventilation reduces the increase in bronchoalveolar lavage fluid high-mobility group Box1 levels and lung water in experimental acute respiratory distress syndrome induced by lung lavage. Eur J Anaesthesiol 2010;27:726-33.

32. Roy SK, Emr B, Sadowitz B, et al. Preemptive application of airway pressure release ventilation prevents development of acute respiratory distress syndrome in rat traumatic hemorrhagic shock model. Shock 2013;40:210-6. 
33. Mahjoubifard M, Jahangiri Fard A, Golestani Eraghi M, et al. Does airway pressure release ventilation mode make difference in cardiopulmonary function of ICU patients? J Cardio-Thorac Med 2015;3:375-8.

34. Yoshida T, Rinka H, Kaji A, et al. The impact of spontaneous ventilation on distribution of lung aeration in patients with acute respiratory distress syndrome: airway pressure release ventilation versus pressure support ventilation. Anesth Analg 2009;109:1892-900.

35. Maxwell RA, Green JM, Waldrop J, et al. A randomized

Cite this article as: Zhong $\mathrm{X}, \mathrm{Wu} \mathrm{Q}$, Yang H, Dong W, Wang B, Zhang Z, Liang G. Airway pressure release ventilation versus low tidal volume ventilation for patients with acute respiratory distress syndrome/acute lung injury: a meta-analysis of randomized clinical trials. Ann Transl Med 2020;8(24):1641. doi: 10.21037/atm-20-6917 prospective trial of airway pressure ventilation and low tidal volume ventilation in adult trauma patients with acute respiratory failure. J Trauma 2010;69:501-10.

36. Bates JH, Irvin CG. Time dependence of recruitment and derecruitment in the lung: a theoretical model. J Appl Physiol 2002;93:705-13.

37. Mireles-Cabodevila E, Kacmarek RM. Should airway pressure release ventilation be the primary mode in ARDS? Respir Care 2016;61:761-3. 